\title{
Ocular Morbidity among Children of Government Schools of Kathmandu Valley: A Follow-up Study
}

Rajesh Kishor Shrestha, ${ }^{1}$ Gauri Shankar Shrestha ${ }^{2}$

'Department of Ophthalmology, Nepal Medical College, Jorpati, Kathmandu, Nepal, '2Department of Ophthalmology, Institute of Medicine, Maharajgunj, Kathmandu, Nepal.

\section{ABSTRACT}

Introduction: Ocular and vision defects are common among school going children. Vision disorders, especially refractive errors are the main disabilities of children and the leading cause of handicapping conditions of childhood. The present study was conducted to find out ocular morbidity among students of government schools of Kathmandu valley.

Methods: In the descriptive and cross-sectional study, 2412 students, comprising of 1114 (46.2\%) males and $1298(53.8 \%)$ females were enrolled in to the study from the five government schools of Kathmandu valley from 2012 to 2013. Detailed eye examination included distance visual acuity testing, anterior and posterior segment examinations, retinoscopy and refraction, cover test, near point of convergence, amplitude of accommodation and color vision test. The Chi-square test was performed to analyze the association between ocular morbidity, age and sex. P value was considered significant at 0.05 for $95 \%$ confidence interval.

Results: Majority of children were age group between 11 and 13 years $(n=783,32.5 \%)$. A male to female ratio was 0.85 . Presenting and best spectacle corrected visual acuity of $6 / 6$ was present in 2257 (93.6\%) and $2380(98.7 \%)$ respectively. Total ocular morbidity was observed in 515 (21.4\%) subjects. The most common types of ocular morbidity were refractive error in 241 (10\%), conjunctivitis in 104 (4.3\%) and convergence insufficiency in $82(3.4 \%)$.

Conclusions: Refractive error, conjunctivitis and convergence insufficiency represent the most common ocular morbidities among students of government schools.

Keywords: conjunctivitis; government school; ocular morbidity; refractive error; students.

\section{INTRODUCTION}

Vision-2020: The Right to Sight has recognized the childhood blindness a major priority owing to the large magnitude of childhood blindness and most cases of childhood blindnesses are avoidable. ${ }^{1,2}$

Prevalence of ocular morbidity and refractive error has been conducted among different groups of children in many parts of Nepal. Way back in 1981, Nepal Blindness Survey identified relatively few cases of the childhood blindness, and the finding mostly comprised of ocular infections, xerophthalmia and congential cataract. ${ }^{3} \mathrm{~A}$ refractive error study from the Mechi zone conducted in 1997 , reported visual morbidity in $2.9 \%$ children ${ }^{4}$ In the recent studies across Nepal, ocular morbidity was reported to range from $9.8 \%$ to $33.7 \% .{ }^{5-10} \mathrm{~A}$ report of a comparative study on ocular morbidity among children of government and private schools of Kathmandu valley

Correspondence: Gauri Shankar Shrestha, Assistant Professor, Department of Ophthalmology, Maharaiguni Medical Campus, Institute of Medicine, Maharajgunj, Kathmandu. Nepal. Email: gs101lg@hotmail. com, Phone: +977-9841019594. 
was presented in 2011 that reported refractive error and strabismus were the major ocular morbidities. ${ }^{11}$

Apart from regular eye examinations among school children, effective and repeated eye examination in school children are necessary in reviewing the progression and changes in pattern of ocular morbidity, managing vision related problems, and minimizing long term visual disability. The present study was conducted to find out the ocular morbidity among school children in government schools of Kathmandu valley. This program is an initiative to provide repeat eye examination, provide appropriate treatment and gather information on ocular morbidity where initial eye examinations were conducted in 2009. ${ }^{11}$

\section{METHODS}

In a descriptive, community based, and cross-sectional study, five government schools in Kathmandu valley were selected for repeat eye examination from 2012 to 2013. All the children attending the schools visited were enrolled into the study. Very few children who were absent at the time of eye examination were left out. They were the students studying from grade one to grade ten. There were a total of 2412 students comprising of 1114 males (46.2\%) and 1298 females $(53.8 \%)$ underwent detailed eye examination. Ethical approval was obtained from the Institutional Review Committee of Nepal Medical College, Teaching Hospital prior to the commencement of the study. The purpose of the study was explained and an informed consent was received from the head of the schools and the parents of the students who were present at the time of eye examination. A team of ophthalmologists, optometrists, and ophthalmic assistants visited each school for the detailed ocular examinations.

Uncorrected, presenting and best spectacle corrected visual acuity (BSCVA) was measured in internally illuminated Snellen vision chart at 6 meters distance. Extraocular movement was performed in six cardinal gazes and cover test and prism cover test was performed using torch light and prism bar both at six metres distance and $40 \mathrm{~cm}$ distance. Near point of convergence and Amplitude of Accommodation were tested using the Royal Air Force (RAF) rule. Color vision was screened with the help of Isihara pseudoisochromatic plates, 38 plates edition. The child was diagnosed as having color vision defect if the child made mistakes in identifying numbers in six or more plates of the chart.

Static retinoscopy and subjective refraction were performed in all children to find out refractive errors. Cycloplegic refraction was carried with $0.5 \%$ cyclopentolate in all the cases of hypermetropia, strabismus, amblyopia, unstable end point of refraction, scissor reflex, anisometropia more than 0.50D, high refractive error, and subjects where vision couldn't be improved with normal refraction. A cyclopentolate $0.5 \%$ drop was instilled three times at an interval of 10 minutes and refraction was carried out after 45 minutes from the first instillation. This process was followed by subjective refraction after three days.

Anterior segment examination was carried out with Haag Streit Slit lamp and posterior segment examination was carried out with Haag Streit Slit lamp with 90D lens and direct ophthalmoscope in all children. All the findings were recorded in the preset proforma.

The diagnosis of myopia and hyperopia was made when the spherical equivalent was 0.50 dioptres, and for astigmatism, error equal to or greater than $0.75 \mathrm{D}$ was considered significant. The diagnosis of amblyopia was made if visual acuity was worse than 6/9 after meticulous refraction in the absence of any ocular pathology. The diagnosis of strabismic amblyopia was made if the reduced visual acuity was due to the strabismus. Similarly, the diagnosis of refractive amblyopia was made if there was anisometropia of 1.00 dioptre for hypermetropia and 4 dioptres for myopia. The students that required further evaluation and treatment were referred to the nearest hospital.

All the data were entered in the statistical package for social studies version 16.0. The Chi-Square test was performed to analyze differences in refractive error between males and females, and among different age groups. The P-value for confidence interval of $95 \%$ was considered significant at 0.05 for prevalence estimates.

\section{RESULTS}

A total of 2412 students comprising of 1114 males $(46.2 \%)$ and females 1298 (53.8\%) were examined between 5 to 16 years of age were examined with mean age of $12.6 \pm 4.2$ years (Table 1). Most of the children ( $n=783,32.5 \%$ ) belonged to the age group 11 to 13 years of age and to the females $(n=1298$, $53.8 \%)$.

\begin{tabular}{|cc|}
\hline $\begin{array}{l}\text { Table 1. Distribution of students by age group and } \\
\text { sex. }\end{array}$ & $\mathbf{n}(\%)$ \\
\hline Characteristics & $384(15.9)$ \\
$5-7$ years & $616(25.5)$ \\
$8-10$ years & $783(32.5)$ \\
$11-13$ years & $629(26.1)$ \\
$14-16$ years & $1114(46.2)$ \\
Males
\end{tabular}


Shrestha et al. Ocular Morbidity among Children of Government Schools of Kathmandu Valley: A Follow-up Study

Females 1298 (53.8)

Presenting visual acuity of $6 / 6$ was noted in 2257 students $(93.6 \%)$ where as visual acuity as less as $3 / 60$ was present in nine students $(0.4 \%)$. Among 40 children who wore spectacle, 6/6 visual acuity was present in only 27 students (Table 2). Best spectacle corrected visual acuity (BSCVA) was noted to be $6 / 6$ in 2385 students $(98.9 \%)$, and visual acuity less than $6 / 12$ was present in only seven students $(0.3 \%)$.

\begin{tabular}{|c|c|c|c|c|}
\hline VA & $\begin{array}{c}\text { Unaided } \\
\text { n (\%) }\end{array}$ & $\begin{array}{c}\text { Presenting } \\
\text { n (\%) }\end{array}$ & $\begin{array}{c}\text { Wearing } \\
\text { glasses } \\
\text { n (\%) }\end{array}$ & $\begin{array}{c}\text { Best } \\
\text { spectacle } \\
\text { corrected } \\
\text { n (\%) }\end{array}$ \\
\hline $6 / 6$ & $\begin{array}{l}2230 \\
(92.5)\end{array}$ & $\begin{array}{l}2257 \\
(93.6)\end{array}$ & $27(1.1)$ & $\begin{array}{l}2380 \\
(98.7)\end{array}$ \\
\hline 6/9-6/12 & $\begin{array}{l}107 \\
(4.4)\end{array}$ & 94 (3.9) & $8(0.3)$ & $\begin{array}{l}20 \\
(0.8)\end{array}$ \\
\hline 6/18-6/60 & $41(1.7)$ & $35(1.4)$ & $5(0.2)$ & $\begin{array}{l}12 \\
(0.5)\end{array}$ \\
\hline$<6 / 60-3 / 60$ & $20(0.8)$ & $17(0.7)$ & - & - \\
\hline$<3 / 60-1 / 60$ & $12(0.5)$ & $9(0.4)$ & - & - \\
\hline$<1 / 60-\mathrm{PL}$ & $2(0.1)$ & - & - & - \\
\hline Total & $\begin{array}{l}2412 \\
(100)\end{array}$ & $\begin{array}{l}2412 \\
(100)\end{array}$ & $40(1.6)$ & $\begin{array}{l}2412 \\
(100)\end{array}$ \\
\hline
\end{tabular}

Prevalence of refractive error is presented in Table 3. A total of 241 students $(10.0 \%)$ had refractive error comprising of 120 males (10.8\%) and 121 females $(9.3 \%)$, and the difference was statistically insignificant $(p=0.26)$. Refractive error was prevalent in $36(9.4 \%)$ students of age group 5 to 7 years, later the error was increased and labeled among 68 (10.8\%) students of age group 14 to 16 years. But this change was insignificant $(P=0.38)$. Distribution of refractive error is presented in Figure 1. Myopia was the most common refractive error in 180 students $(74.7 \%)$. Frequency of myopia comprised of 95 males (79.2\%) and 85 females $(70.2 \%)$, and that was insignificantly $\left(\chi^{2}=3.4, \mathrm{df}=1, \mathrm{P}=0.06\right)$ higher among males than females. Hypermetropia was noted among 36 females (29.8\%) and 25 males (20.8\%). However, there was no significant difference between them for hypermetropia as well $\left(\chi^{2}=0.7, \mathrm{df}=1, \mathrm{P}=0.4\right)$.

\begin{tabular}{|c|c|c|c|c|}
\hline \multirow{2}{*}{$\begin{array}{l}\text { Age and sex } \\
\text { distribution }\end{array}$} & \multicolumn{2}{|c|}{ Refractive error } & \multirow[t]{2}{*}{$P$ value } & \multirow[t]{2}{*}{ OR (CI) } \\
\hline & $\begin{array}{c}\text { Present } \\
\text { n (\%) }\end{array}$ & $\begin{array}{c}\text { Absent } \\
\text { n (\%) }\end{array}$ & & \\
\hline $\begin{array}{l}5-7 \text { years } \\
(n=384)\end{array}$ & $36(9.4)$ & $\begin{array}{l}238 \\
(90.6)\end{array}$ & 0.06 & $\begin{array}{l}1.5(1.0- \\
2.2)\end{array}$ \\
\hline
\end{tabular}

\begin{tabular}{|lllll|}
$8-10$ years & $58(9.4)$ & 558 & 0.64 & $1.0(0.7-$ \\
$(n=616)$ & & $(90.6)$ & & $1.3)$ \\
$11-13$ years & 79 & 704 & 0.86 & $1.1(0.8-$ \\
$(n=783)$ & $(10.1)$ & $(89.9)$ & & $1.4)$ \\
$14-16$ years & 68 & 561 & 0.39 & $1.2(0.9-$ \\
$(n=629)$ & $(10.8)$ & $(89.2)$ & & $1.6)$ \\
Males & 120 & 994 & 0.17 & $1.2(0.9-$ \\
$(n=1114)$ & $(10.8)$ & $(89.2)$ & & $1.5)$ \\
Females & 121 & 1177 & 0.23 & $0.8(0.6-$ \\
$(n=1298)$ & $(9.3)$ & $(91.7)$ & & $1.0)$ \\
Total & 241 & 2171 & & \\
& $(10.0)$ & $(90.0)$ & & \\
\hline P value significance at 0.05 by chi-square test; OR=odds ratio
\end{tabular}

$C I=95 \%$ confidence interval; $O R=$ Odds ratio

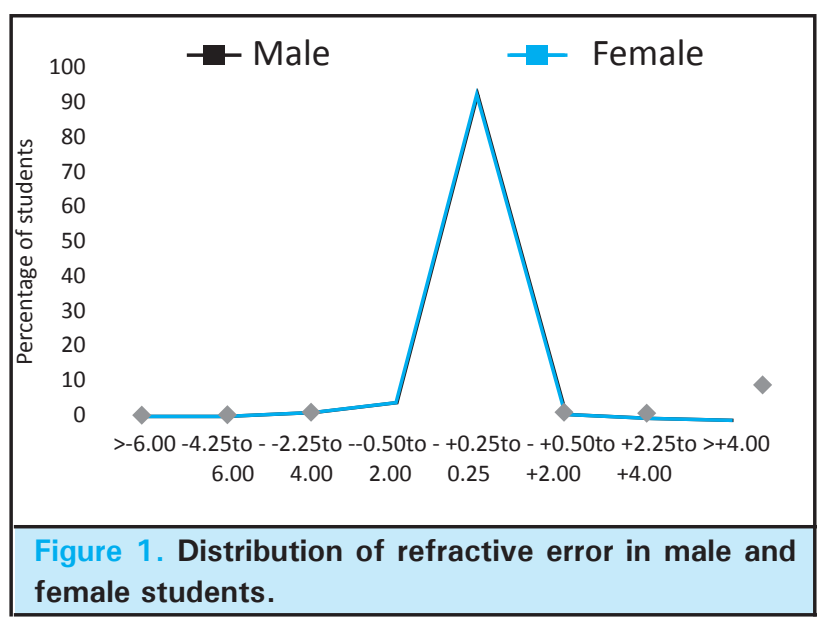

Out of 2412 students examined, 515 students (21.4\%) noted to have some form of ocular morbidity (Table 4). A total of $102(19.8 \%)$ children developed two or more ocular morbidity. Ocular morbidity was found to be significantly higher among males compared to females $(\mathrm{P}=0.00$, Odd $2.1 ; 95 \% \mathrm{Cl}, 1.7-2.6)$. Various category of ocular morbidity is presented in Figure 2. The most common ocular morbidity was refractive error in 241 children $(10.0 \%)$ followed by the conjunctivitis in 104 children $(4.3 \%)$ and the convergence insufficiency in 82 children (3.4\%). The conjunctivitis consisted of both infective and allergic types. Among 66 students (2.7\%) having accommodative insufficiency, 24 children had convergence insufficiency as well. Among 61 students $(2.5 \%)$ having blepharitis, mixed blepharitis was noted in 30 students. Among 32 children (1.3\%) with amblyopia, five children (15.6\%) had strabismic amblyopia, associated with exotropia in three students and esotropia in two students, 15 children (46.9\%) had anisostrabismic amblyopia and rest of 12 students (37.5\%) had refractive amblyopia. Among 40 (1.7\%) strabismic students, exotropia was seen in 26 (65\%) students and esotropia was seen in 14 students (35\%). Among 12 children with corneal opacity, nine children develop corneal opacity due to trauma and 
three children develop corneal opacity due to corneal infections. Two cases with cataract were traumatic in origin and associated with corneal opacity. Among 10 miscellaneous cases, diagnosis consisted of two cases proptosis, one case of juvenile glaucoma, two cases of nystagmus, two cases of retinal scars, one case of keratoconus and two cases of glaucoma suspects.

\begin{tabular}{|lllll|}
\hline \multicolumn{5}{|l}{ Table 4. Distribution of ocular morbidity in students. } \\
\hline $\begin{array}{l}\text { Age } \\
\text { and sex } \\
\text { distribution }\end{array}$ & $\begin{array}{l}\text { Ocular morbidity } \\
\text { Present }\end{array}$ & $\begin{array}{l}\text { Absent } \\
\text { no (\%) }\end{array}$ & $\begin{array}{l}\text { P } \\
\text { value }\end{array}$ & OR (CI) \\
$\begin{array}{l}\text { 5-7 years } \\
(\mathrm{n}=384)\end{array}$ & $92(23.9)$ & $292(76.1)$ & 0.17 & $1.2(0.9-1.5)$ \\
$\begin{array}{l}8-10 \text { years } \\
(\mathrm{n}=616)\end{array}$ & $132(21.4)$ & $484(78.6)$ & 0.95 & $1.0(0.8-1.2)$ \\
$\begin{array}{l}11-13 \text { years } \\
(\mathrm{n}=783)\end{array}$ & $184(23.5)$ & $599(76.5)$ & 0.07 & $1.2(1.0-1.5)$ \\
$\begin{array}{l}14-16 \text { years } \\
(\mathrm{n}=629)\end{array}$ & $107(17.0)$ & $522(83.0)$ & 0.002 & $0.7(0.5-0.9)$ \\
$\begin{array}{l}\text { Males } \\
(\mathrm{n}=1114)\end{array}$ & $312(28.0)$ & $802(72.0)$ & 0.00 & $2.1(1.7-2.6)$ \\
$\begin{array}{l}\text { Females }(\mathrm{n}= \\
1298)\end{array}$ & $203(15.6)$ & $1095(84.4)$ & 0.00 & $0.5(0.4-0.6)$ \\
Total & $515(21.4)$ & $1897(78.6)$ & & \\
\hline
\end{tabular}

$\mathrm{P}$ value significance at 0.05 by chi-square test $\mathrm{CI}=95 \%$ confidence interval; $\mathrm{OR}=$ Odd's ratio

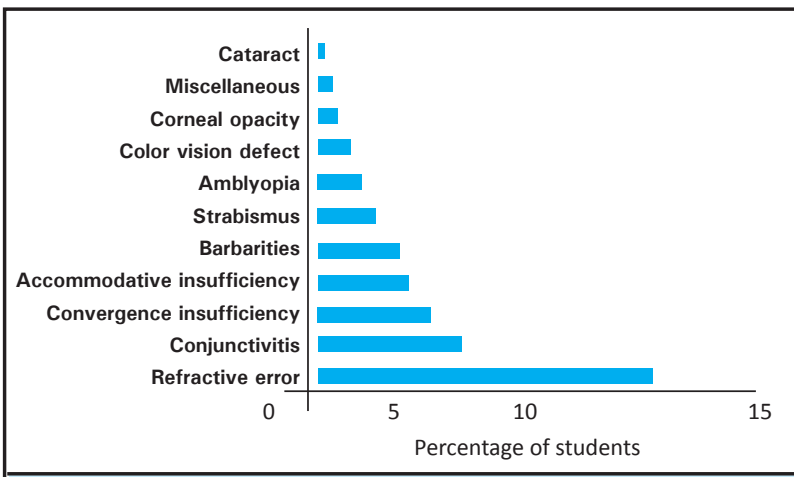

Figure 2. Distribution of ocular morbidity.

\section{DISCUSSION}

The present study reports the pattern of ocular morbidity among students of government schools of Kathmandu. We have already presented ocular morbidity profile among students of private and government schools of Kathmandu. ${ }^{11}$ In present study, we have selected the same government schools where eye examination was carried out in 2009. ${ }^{11}$

The total ocular morbidity in the present study is 515 $(21.4 \%)$. This finding is slightly higher than findings of our previous study that is $404(18.7 \%)$ among students of government schools. ${ }^{11}$ The prevalence of ocular morbidity is more common in males than females ( $p=0.00$; Odds $2.1 ; 95 \% \mathrm{Cl} 1.7-2.6)$. There are also variable findings on prevalence of ocular morbidity among children in different studies conducted in Kathmandu that ranges from $9.8 \%$ to $33.7 \% .^{5-10,12}$ They included the children of private schools, government schools, primary school, squatter settlements and street children. This variation in morbidity can also be caused by variation in age range, research settings, sample size and sampling design.

In the study, refractive error is the major cause of ocular morbidity in $241(10 \%)$ students. These findings are quite aligned with our previous study with 242 (10.6\%) students in government schools. ${ }^{11}$ However different study has variable prevalence of refractive error in Nepal that Sherpa et al, $(2011,2014)$ reported among 11 children (2.4\%) and 31 children (9.3\%) among primary school children, ${ }^{9,10} \mathrm{Nepal}$ et al, (2003) reported it among $89(8.1 \%)$ government school of rural area, ${ }^{6}$ Shrestha et al, (2006) reported it among 398 (21.9\%) private school children, ${ }^{5}$ Pokhrel et al, (2010) reported it among $20(19.8 \%)$ school children of rural and urban settings of Nepal ${ }^{13}$ and Shrestha et al, (2011) reported it among 192 (8.6\%) school children of Jhapa. ${ }^{14}$ This variation is also well explained by variable research settings, geographical variation, types of schools and age groups of the study population. However, the common entity that all the studies have shared, is the presence of myopia as a common refractive error except Sherpa et al, (2011) study which is conducted among primary school children. ${ }^{9}$ In our study, myopia accounts for $180(74.7 \%)$ of total refractive errors.

The conjunctivitis among 104 cases (4.3\%) and blepharitis among 82 cases $(2.5 \%)$ also constitute a major threat to ocular health conditions in our study. These conditions can be easily tackled by instituting proper treatment and can be prevented by teaching how to maintain proper ocular hygiene. Conjunctivitis is reported to be as low as $0.6 \%$ to as high as $11.9 \%$ in various studies conducted in Nepal. ${ }^{8-10,12,14}$ Lid related conditions and blepharitis are reported to range from $0.8 \%$ to $9.6 \% .^{7,9,10,12}$ These studies were conducted among school children ${ }^{9,10,14}$ orphanages of Kathmandu, ${ }^{8}$ street children ${ }^{12}$ and children of squatter settlement ${ }^{7}$. Like in the previous studies, ${ }^{7,10,11}$ convergence and accommodation are also commonly noted in our study among $82(3.4 \%)$ and $65(2.7 \%)$ students respectively.

Uncorrected, presenting and best spectacle corrected visual acuity (BSCVA) of 6/6 is present in 2230 (92.5\%), $2257(93.6 \%)$ and $2330(98.7 \%)$ respectively. There is an agreement in finding of visual acuity in the literature. ${ }^{14}$ Prevalence of amblyopia and strabismus 
has been noted to be $31(1.3 \%)$ and $41(1.7 \%)$ in our study. The more common entities are aniso-strabismic amblyopia and exotropia. In the literature amblyopia and strabismus are reported in the range from $0.13 \%$ to $2.0 \% \%^{5,7,9,11,14}$ and $0.6 \%$ to $3.2 \%^{5-7,11}$ respectively. Although amblyopia and strabismus represent a small proportion of ocular morbidity, the consequences of these conditions can't be neglected for their nature of permanent visual impairment if cure is not initiated on time. So an effective intervention has to be initiated timely to tackle such conditions.

In summary, we have compared a pattern of ocular morbidity among students between previous report of government schools ${ }^{11}$ and the present report of the same government schools. Though refractive error has remained to be the stable and leading cause of ocular morbidity, ocular infections among 157 (6.8\%) students, such as conjunctivitis and blepharitis are more commonly seen in present study than previous one among 45 $(1.95 \%)$ students. Similarly strabismus is less prevalent among $41(1.7 \%)$ students at present eye examination than previous one among 71 students $(3.13 \%)$ where as amblyopia is seen more in present study among 31 students $(1.3 \%)$ than previous one among three students $(0.15 \%)$. Accommodative insufficiency is significantly noted in present study. However previous study, accommodative insufficiency was not reported rather mean amplitude of accommodation was only presented as $7.27 \mathrm{~cm}$. The present study suggests that children have to be taught more about importance of maintaining hygiene and environmental sanitation to improve their hygiene behaviour. This issue can be tackled by introducing health programs at schools and periodic eye examination.

Limitation of the present study is lack of enumeration of school children to compare the real change in the ocular morbidity, though we conducted the eye program in the same government schools. Another limitation is in its generalization that the sample is being taken from only a few schools.

\section{CONCLUSIONS}

Children of government schools have significant ocular morbidity, especially refractive error, conjunctivitis and convergence insufficiency being the most common causes. The periodic eye examination is necessary to assess changes in pattern of ocular morbidity and plan interventions.

Conflict of Interest: None.

\section{REFERENCES}

1. Pizzarello L, Abiose A, Ffytche T, et al. Vision 2020: The right to sight: a global initiative to eliminate avoidable blindness. Arch Ophthalmol. 2004 Apr;122(4):615-20. [PubMed | DOI | Full Text]

2. Steinkuller PG, Du L, Gilbert C, Foster A, Collins ML, Coats DK. Childhood blindness. J AAPOS 1999 Feb;3(1):26-32. [PubMed | DOI | Full Text]

3. Brilliant LB, Pokhrel RP, Grasset NC, et al. Epidemiology of blindness in Nepal. Bull World Health Organ. 1985;63(2):375-86. [PubMed | Full Text]

4. Pokharel GP, Negrel AD, Munoz SR, Ellwein LB. Refractive error study in children: results from Mechi Zone, Nepal. Am J Ophthalmol. 2000 Apr;129(4): 436-44. [PubMed | DOI]

5. Shrestha RK, Joshi MR, Ghising R, Pradhan P, Shakya S, Rizyal A. Ocular morbidity among children studying in studying in private school of Kathmandu Valley: A prospective cross-sectional study. Nepal Med Coll J. 2006 Mar;8(1):43-6. [PubMed]

6. Nepal BP, Koirala S, Adhikary S, Sharma AK. Ocular morbidity in school children in Kathmandu. Br J Ophthalmol. 2003 May; 87(5):531-4. [PubMed | Full Text]

7. Shrestha GS, Manandhar S, Joshi ND, Shrestha JK. Ocular morbidity among the children of squatter settlements in Kathmandu. Optom Vis Sci. 2013 Sep;9(9):1012-8. [PubMed | DOI]
8. Shrestha MK, Wolf L, Shrestha U, et al. Ocular morbidity among orphanage. JNMA J Nepal Med Assoc. 2010 Jan-Mar;49(177):29-32. [PubMed]

9. Sherpa D, Pant CR, Joshi ND. Ocular morbidity among primary school children of Dhulikhel Nepal. Nepal J Ophthalmol. 2011 Jul-Dec;3(2):172-6. [PubMed | Full Text]

10. Sherpa D. Ocular morbidity among primary school children. J Chitwan Med Coll. 2014;4(2):32-4. [PubMed | DOI |Full Text]

11. Shrestha RK, Joshi MR, Ghising R, Rizyal A. Ocular morbidity among children attending government and private schools of Kathmandu valley. JNMA J Nepal Med Assoc. 2011 Oct-Dec;51(184):182-8. [PubMed | Full Text]

12. Pant M, Shrestha GS, Joshi N. Ocular morbidity among street children in Kathmandu valley. Ophthalmic Epidemiol. 2014 Dec;21(6):356-61. [PubMed | DOI]

13. Pokharel A, Pokharel PK, Das H, Adhikari S. The patterns of refractive error among the school children of rural and urban settings in Nepal. Nepal J Ophthalmol. 2010 Jul-Dec; 2(2):114-20. [PubMed | DOI | Full Text]

14. sShrestha GS, Sujakhu D, Joshi P. Refractive error among school children in Jhapa Nepal. J Optom. 2011 Apr;4(2): 49-55. [PubMed | DOI | Full Text] 